\title{
Pediatric Endocrinology Terminology
}

National Cancer Institute

\section{Source}

National Cancer Institute. Pediatric Endocrinology Terminology. NCI Thesaurus. Code C118467.

Terminology developed by a collaborative effort of the National Cancer Institute's Enterprise Vocabulary Services, the National Institute of Child Health and Human Development, and an international group of clinicians and informaticists to support the reporting of events in the pediatric population that are related to endocrine disorders. 